\title{
Cuerpo y "Misticismo" en las Misas de Sanación del Movimiento de Renovación Carismática Católico en Mérida (VenezUela)
}

\author{
Francisco Franco
}

Resumen: El movimiento de Renovación Católica Carismática se ha constituido en una posibilidad religiosa contemporánea importante en Venezuela, compitiendo con otras religiones. De ser un grupo marginal dentro de la Iglesia católica su influencia ha crecido, aunque con un cierto apoyo de la jerarquía eclesiástica. Por todo el país, los sacerdotes carismáticos ofician sus misas de sanación con una presencia masiva de fieles inédita en años anteriores. En este artículo, mostraremos algunos de los resultados del trabajo etnográfico realizado durante el año 2006 en iglesias católicas de la ciudad de Mérida (Venezuela), donde se llevan a cabo "Misas de Sanación" dirigidas por sacerdotes carismáticos. Mostraremos cómo en las vivencias y en la ritualidad de la renovación carismática, plasmadas en esas Misas de Sanación, el cuerpo es el ordenador de esta revitalización, es el centro de su ritualidad lo que principalmente ha contribuido a que este movimiento compita de manera exitosa con los grupos pentecostales y con el Culto a María Lionza y con la forma tradicional del catolicismo, de alli su enorme crecimiento en los últimos años. Planteamos que este ritual ha renovadoy "subvertido" la tradicional homilía católica, destacando los distintos momentos rituales del evento, mostrando la importancia de la sensualidad, del cuerpo y de los sentidos en esta ceremonia religiosa. El cuerpoes marcado, enél sejuegay evidencia la "verdad" y la eficiencia de la ritualidad carismática. Sin embargo, señalamos que este movimiento de renovación, se inscribe en una tradición cristiana mística, un camino hacia la búsqueda de dios a través del cuerpo y de experiencias extáticas que van desde el martirio, la ascesis y la escritura mística pero aquí se convierte en una especie de misticismo cotidiano o light.
Abstract: The movement of Charismatic Catholic Renovation has been constituted in an important contemporary possibility religious in Venezuela, competing with other religions. Of being a marginal group within the Catholic Church its influence has grown, although with a certain support of the ecclesiastical hierarchy. By all the country, the charismatic priests celebrate their Healing Mass with unpublished a massive presence of faithfuls in previous years. In this article, we will show some of the results of the ethnographic work carried out during the 2006 in catholic Churches of the city of Merida (Venezuela), where Healing Mass are carried out directed by charismatic priests. We will show how in the experiences and the performance of the charismatic renovation, shaped in those Healing Mass, the body is the computer of this revitalisation, is the center of its rituals which mainly has contributed to that this movement competes of successful way with the pentecostals groups and the Cult to Maria Lionza and the traditional form of the catholicism, of there its enormous growth in the last years. Weraise that this ritual has renewed and "subverted" the traditional catholic homily, emphasizing the different ritual moments from the event, showing the importance of the sensuality, the body and the senses in this religious ceremony. The body is marked, in him it gambles and it demonstrates the "truth" and the efficiency of the charismatic ritual. Nevertheless, we indicated that this movement of renovation, register in a mystical Christian tradition, a way towards the search of God through body and of ecstatics experiences that go from the martyrdom, the ascetic and the mystical writing but becomes a species of daily mysticism here or light. 
Palabras clave: movimiento carismático, carisma, pentecostal, misas de sanación, cuerpo, misticismo, Venezuela.
Keywords: charismatic movement, charisma, pentecostals, healing mass, mysticism, body, Venezuela.
$\Psi_{y}$ ste artículol se origina de una inquietud personal y académica. La primera está vinculada con mi formación inicial religiosa como católico y con la curiosidad que de joven sentía por la religión entonces, equivalente para mí al catolicismo-. Pero, aquel interés fue muy poco estimulado por la Iglesia que frecuentaba, hasta el punto que casi todo lo relacionado con "lo religioso" terminó por aburrirme. Actitud que se convirtió en franca oposición por la insistencia obligada de mis padres a que asistiera a la misa de domingo. Si bien no puedo obviar mi condición de adolescente en aquella época para explicar aquel rechazo, aún continúo experimentando una notable resistencia hacia las misas católicas y un fastidio difícil de superar. Algo de este malestar debe tener su base en la "incompetencia" que menciona Certeau (1993) en el texto que sirve de epígrafe a este artículo. Por todo esto, quedé perplejo cuando en 2004 escuché hablar del entusiasmo masivo que las "misas de sanación" de la Renovación Carismática Católica producían en Venezuela.

La otra inquietud que origina este texto por supuesto es académica y se basa en la relevancia que las "misas de sanación" de la Renovación Carismática Católica ostentan desde - por lo menos- hace más de quince años en toda Venezuela. Numerosas parroquias ofician misas muy distintas a las tradicionales homilías

Enviado a dictamen: 15 de agosto de 2010

Aprobación: 15 de septiembre de 2010

Revisiones: 1

Francisco Franco, Licenciado en Historia, graduado en la Escuela de Historia de la Universidad de Los Andes (Mérida). Magíster en Etnología en la misma universidad. Profesor Agregado del Dpto. de Antropología y Sociología, Escuela de Historia. Universidad de Los Andes. Temas de especialidad: historia y antropología. Página web: webdelprofesor.ula.ve/humanidades/franco. Correo electrónico: franco@ula.ve. católicas, logrando atraer una cantidad enorme, no vista antes, de fieles católicos apasionados a los templos católicos. Sin embargo, a pesar de su crecimiento y su desarrollo el movimiento está por estudiarse, las investigaciones sobre el tema en Venezuela son prácticamente inexistentes; hay muy pocos estudios históricos, antropológicos o sociológicos, así como no los hay acerca del pentecostalismo, hermano gemelo de aquel. La mayoría de los pocos trabajos con los que se cuentan tienen una perspectiva confesional y son muy generales, otros buscan establecer una comparación con el culto de María Lionza. Hace falta, especialmente, investigaciones particulares históricas y con enfoques etnográficos (Ayerra 1980; Castillo 1992; Flores 1990; Ganuza 1978; García Gavidia 1987; Rivas Sarache 1991; Macia 1997; Pollak-eltz 2000; Mercado 2006). Por otra parte, no contamos con estadísticas, censos o información cuantitativa de estos u otros grupos religiosos, ya que, por una parte, en Venezuela los censos oficiales no incluyen preguntas sobre la confesión religiosa y, por otra, no existen investigaciones que aborden el problema religioso desde una perspectiva estadística.

\section{El movimiento de Renovación Carismática Católica}

Este movimiento ${ }^{1}$ se inicia en Venezuela a comienzos de la década de los setenta del siglo XX gracias al trabajo de sacerdotes extranjeros. En esos años se experimentó en el país un breve florecimiento, aunque fueron estigmatizados por los católicos tradicionales quienes estimaban sus prácticas religiosas excesivas, "raras" y demasiado parecidas a la de los evangélicos pentecostales. ${ }^{2}$ Desde sus comienzos, sus rituales — casi exclusivamente- se circunscribieron a los "círculos 
de oraciones"; grupos de personas que oraban por la salud y el bienestar de sus adeptos, invocaban la gracia del Espíritu Santo entrando en trance y "hablando en lenguas". La mayoría de las veces realizaban estos rituales fuera de las iglesias, no necesariamente con la participación de un sacerdote. Estos primeros carismáticos mostraban una actitud vehemente incluso en la forma de manifestar su piedad cuando asistían a las misas de domingo, de allí el calificativo de "raros" que le endosaban los católicos tradicionales. Entre mediados y finales de los años ochenta del siglo pasado resurge este movimiento con las llamadas "misas de sanación", que se propagan de manera exponencial por todas las parroquias del país, esta vez con un importante apoyo de sacerdotes y de algunos prelados de la jerarquía eclesiástica.

La expansión de los carismáticos en la actualidad continúa con su evento principal: la "misa de sanación". Esta se realiza durante el domingo o en ocasiones especiales, desplegando publicidad y, a veces, fuera de los templos católicos. ${ }^{3}$ Este ritual los identifica y los diferencia de los católicos tradicionales, aunque muchos adeptos y sacerdotes no se reconocen como carismáticos sino sencillamente como católicos. Esta postura, tal vez, se deba a un intento de autoidentificarse como católico y asumir que el "movimiento carismático" simplemente es una renovación dentro del catolicismo (ver nota 1). También algunos adeptos identifican la institución eclesiástica toda con su movimiento de renovación, tal vez porque han pasado de un estatus "marginal" a ostentar un enorme prestigio, gracias al notable crecimiento que han experimentado dentro del seno de la Iglesia. Así pues, las discrepancias con el catolicismo tradicional en la práctica de la homilía o la misa son ostensibles e indudables; incluso, proclaman una diferencia con el católico tradicional en cómo deben asumir la piedad cotidiana.

Por su parte, la jerarquía eclesiástica venezolana parece exhibir un apoyo fluido pero sin vehemencia a este movimiento. Los conflictos no dejan de suscitarse entre los sacerdotes carismáticos y los que no los son, probablemente porque los primeros atraen a una numerosa feligresía en detrimento de la clientela de los segundos. Por supuesto, en este nivel existen diferencias doctrinales y en cómo debe realizarse la ritualidad de la misa católica. No hemos encontrado documentos oficiales de la Iglesia Venezolana sobre el movimiento carismático. Lo más cercano a esto es el Documento del Encuentro Episcopal Latinoamericano efectuado en La Ceja (Colombia), de septiembre de 1987, titulado: "La Renovación Espiritual Católica Carismática"4, donde participaron por Venezuela un arzobispo y seis obispos. ${ }^{5}$ Llama la atención que este documento aclara que no es oficial sino que fue firmado "a título personal por la mayoría de los participantes”, no obstante, los obispos debían difundirlo en sus respectivas diócesis para fijar así los criterios que podían "animar y orientar la Renovación” en Latinoamérica (Encuentro Episcopal Latinoamericano, 1987: 1). Si bien la clase y el tipo de apoyo que la jerarquía eclesiástica en Venezuela presta al movimiento están por estudiarse, este documento evidencia un aliento débil, a la vez que una preocupación y una intención de influir y controlar a Renovación Carismática Católica. Asimismo, la proliferación de "misas de sanación" por todo el país, durante la última década, sin conflictos con la institución, muestra por lo menos una tolerancia estratégica de las esferas eclesiásticas. ${ }^{6}$ Podríamos establecer como apoyo a esta hipótesis los siguientes elementos:

Primero, es una estrategia eclesiástica para enfrentar el crecimiento exponencial que han experimentado las iglesias pentecostales; los carismáticos, muy parecidos a estas, servirían como dique de contención contra este "preocupante" incremento. Incluso, muchos pentecostales son atraídos -o podrían serlo- hacia las misas de sanación por lo parecido de estos rituales con los que practican en sus propias iglesias. ${ }^{7}$

Segundo, muchos altos prelados manifiestan una verdadera militancia en el movimiento carismático, por ejemplo, se comentan entre fieles de las misas 
de sanación que uno de los seminarios para formar sacerdotes más importante de Venezuela —el de la ciudad de Mérida - es dirigido por un sacerdote carismático o por lo menos es un convencido de la importancia de este movimiento de renovación para la Iglesia católica venezolana, entonces, la misma Iglesia estaría formando sacerdotes dentro de esta corriente. Igualmente, el arzobispo de Barquisimeto, donde se encuentra la sede oficial de la Renovación Carismática Católica, Tulio M. Chirivella V. ${ }^{8}$, jubilado en 2008, es desde hace más de una década reconocido como claro líder de la Renovación Carismática en el país.

Tercero, las misas de sanación ayudan a la Iglesia católica a competir con el llamado culto de María Lionza o espiritismo, culto de posesión, ${ }^{9}$ como también lo son los movimientos carismáticos y pentecostales. La lucha entre estos se observa en Venezuela el 12 de octubre - día de fiesta nacional, oficialmente antiguo "Día de la Raza", ahora "Día de la Resistencia Indígena"-, cuando los pentecostales de diversas denominaciones realizan una marcha en muchas ciudades venezolanas para combatir todo tipo de brujería y la magia, haciendo referencia principalmente a las prácticas de los adeptos de María Lionza o espiritismo, como se le conoce entre sus practicantes. ${ }^{10}$ También competiría con una nueva forma religiosa "mundial" donde la magia es parte de las representaciones y la ritualidad, el cual se conoce como "New Age" o "Nueva Era". No es un grupo o una religión como tal, es una corriente religiosa de difícil definición que comprende un sinnúmero de agrupaciones distintas y diversas, toma elementos, rituales y creencias de distintas tradiciones, esoterismos orientales y occidentales, renueva prácticas antiguas y reinventa otras con un cariz novedoso y moderno. Incluye grupos y discursos que se conocen como de "autoayuda". Es un "movimiento" que no es exclusivo o nacido en Latinoamericana sino más bien posmoderno, contemporáneo y, se podría decir, existe en distintas formas por todas partes del mundo. ${ }^{11}$
Como vemos, en el "mercado" religioso venezolano compiten, por lo menos, cuatro formas religiosas ${ }^{12}$ pentecostalismo, renovación carismática, catolicismo tradicional, y el culto a María Lionza- que deben ser entendidas interrelacionadas, no como un macrosistema sino más bien como sistemas distintos de representaciones y prácticas donde los venezolanos, no sin conflictos, se desplazan física y simbólicamente, transitando por uno y otro, estableciendo "estados de ánimos y motivaciones" — como dice Geertz (1989) - , explicándose y comprendiendo el mundo y, por supuesto, intentando satisfacer sus necesidades. Como señala Vallverdú (2001) sobre los carismáticos en Latinoamérica:

...la pluralización y segmentación del fenómeno religioso no conducen necesariamente a la irrelevancia social de la religión o a su desaparición, sino a una nueva forma de relación con la modernidad. Las formas religiosas contemporáneas tienden a la disgregación, a la fragmentación, a la movilidad. Una especie de "nuevo supermercado espiritual y del sentido" toma forma en nuevos contextos ideológicos y de búsqueda de significados ( $\mathrm{s} / \mathrm{p})$.

\section{Renovación Católica Carismática en la ciudad de Mérida}

En este artículo, como acercamiento preliminar, mostraremos algunos de los resultados del trabajo etnográfico realizado en 2006 en iglesias católicas de la ciudad de Mérida, Venezuela, en las cuales se llevaban a cabo las llamadas "misas de sanación" dirigidas por sacerdotes carismáticos, quienes se han constituido en verdaderos líderes que pretenden renovar el catolicismo. En específico, hicimos trabajo de campo en tres parroquias de la ciudad de Mérida: la iglesia del Llano, la iglesia de Milla, y la iglesia de Santa Bárbara, en esta última donde asisten gran cantidad de fieles de clase media; sin embargo hemos trabajado, sobre todo, 
en una parroquia de un pueblo cercano de Mérida, Mucuchíes, pueblo agrícola, donde el sacerdote de esta comunidad atrae miles de adeptos de la ciudad de Mérida y de otras partes del país. Este sacerdote, en particular, se ha constituido en un verdadero líder regional del catolicismo venezolano, con sus misas de sanación, su intervención en la vida del pueblo y su gran carisma. ${ }^{13}$

En este culto fundamentalmente urbano ${ }^{14}$ parece redefinirse la relación entre los sacerdotes católicos con su comunidad. Si bien en otras épocas el sacerdote fue un personaje importante para la feligresía católica, su papel fue perdiendo protagonismo, tal vez por el acelerado crecimiento de las ciudades y la multiplicación de ofertas religiosas. El sacerdote carismático de las misas de sanación, en algunos casos, se ha convertido tanto en un líder religioso como en líder de su comunidad; a caballo entre el pastor evangélico y aquel sacerdote "comprometido" de la teología de la liberación, pero ya sin radicalismos políticos. ${ }^{15}$

A continuación estudiaremos la misa de sanación que ha renovado y "subvertido" la tradicional homilía católica, destacando los distintos momentos rituales del evento. Mostrando cómo en las vivencias y ritualidad carismática el cuerpo es el ordenador de esta revitalización, lo que la hace de manera eficiente competir con los grupos pentecostales, de allí su enorme crecimiento en los últimos años, ${ }^{16}$ y principalmente contra el culto a María Lionza. Por otra parte, intentaremos mostrar que este movimiento, aunque calificado de renovación, se inscribe en una tradición cristiana mística, un camino hacia la búsqueda de dios a través del cuerpo y experiencias extáticas que van desde el martirio, la ascesis hasta la escritura mística (Certeau, 1993).

\section{Las "misas de sanación”}

El ritual de la misa de sanación, como es llamada por sus adeptos, es el centro del culto carismático. Desde un punto de vista litúrgico, la homilía que realizan estos sacerdotes es la misma que tradicionalmente se ha realizado en la Iglesia católica; sin embargo, los mismos asistentes y fieles reconocen que no es así. Puede durar en algunos casos hasta tres horas y en ocasiones especiales se realizan dentro de eventos mayores, vigilias o sucesos especiales que, a veces, alcanzan una duración de varios días, con la asistencia de numerosos fieles. ${ }^{17}$

La estructura de la misa podemos dividirla en cinco momentos:

1. Introducción o calentamiento, donde el grupo musical — que es parte esencial de la celebraciónva preparando a los fieles, avivando los ánimos y la voluntad para cantar, aplaudir y mover el cuerpo. Se cantan canciones que ya se conocen y tempranamente se va sintiendo la emoción colectiva. En este momento inicial, el parecido de la misa de sanación con cualquier concierto de música es obvio. La mañana siguiente a la vigilia se inicia con cantos previamente preparados y con oraciones, en las que se exalta la grandeza de Dios, de Jesús y del Espíritu Santo. Esta sesión de cantos no corresponde siempre con los cantos católicos comunes, en los que el ritmo es pausado y apagado acompañado frecuentemente por la guitarra clásica. En estas "misas revolucionarias" - como las califican algunos de sus fieles - se canta, se brinca, se salta, se baila las alabanzas a Cristo y a Dios, al ritmo del pop, del rock, del vallenato, de la salsa y otras melodías populares; por ello es común el uso de la batería, la guitarra eléctrica, el bajo y el teclado. Desde el comienzo del ritual, la música ayuda y estimula a que la muchedumbre congregada dance y grite alabanzas a Dios, contrario a la tradicional homilía católica que prohíbe gritar y cantar en los templos, en estas es fundamental la adoración a Dios con la voz, con las palmas e, incluso, con los pies. Los sacerdotes, hasta el cansancio, recuerdan la importancia de adorar a Dios con todo el cuerpo. Como lo afirma uno de ellos, el "Ministerio de Música" es uno de los más importantes dentro del equipo de trabajo, pues "el que canta ora dos veces" y "el que canta y baila ora tres”, mientras más se 
entregue el adepto a estos cantos y oraciones más dones recibirá del Espíritu Santo.

2. Entradadel sacerdote, se inicia la homilía propiamente dicha. Esta entrada puede, a veces, ser espectacular, el sacerdote en ocasiones es un verdadero showman quien se ha apropiado de los gestos y la retórica de los animadores de televisión..$^{18}$ El sacerdote inicia la misa animando y cantando con el grupo, siempre improvisando; frecuentemente recurre a la novedad en el ritual. En una ocasión Carlos Zambrano, por ejemplo, pidió a sus monaguillos agua, sal y unas ramas, con esto improvisó una especie de bautizo para todo el público asistente. El cura, con un gran recipiente donde mezcló agua y sal, caminaba por todo el recinto, rociando a todos con las ramas llenas de agua, estos se agolpaban por donde pasaba el cura y solicitaban ansiosos la aspersión y la bendición que, al son de las canciones, ofrecía de manera enérgica. Este performance lo improvisó luego de recordar un pasaje de la Biblia donde Jesús con agua y sal le concede la fertilidad a una mujer; condensa en este efímero ritual —que antes nunca había realizado - una serie de elementos simbólicos sagrados y profanos. En el relato que le da pie para improvisar el ritual, la fertilidad que Cristo ofrece a la mujer es símbolo de la "fecundidad en la fe" que él promueve en sus fieles y que cada uno de los católicos según el sacerdote - debe avivar en sí mismo. Además, es un simulacro de bautizo, de bendición. También es un espejo en negativo del "despojo", ritual que se hace en el culto a María Lionza; el médium o "materia", que recibe a los espíritus, "despoja" a los creyentes, limpiándolos "espiritualmente" de todas las energías negativas o maleficios arrojados por personas enemigas. Es también un simulacro del juego de carnaval, ya que la homilía en la que improvisó el ritual se realizaba en plena época de carnaval, período en el cual, en la ciudad de Mérida y en toda Venezuela, se acostumbra a "jugar con agua", la gente se moja entre sí como un juego de carnaval en las calles, en sus vecindarios y sus casas. El ritual improvisado mantuvo a los asistentes tanto entretenidos como en un cierto estado de recogimiento, esperando la bendición y el "despojo" que el padre oficiaba. Como afirma Barrera Rivera (2002) sobre los pentecostales - y aquí extendemos esta idea hacia los carismáticos-:

Estas Iglesias han tenido éxito escapando de la rutina. El análisis sociológico del poder religioso muestra lo inevitable de la rutina conforme se avanza en la institucionalización... Los líderes pentecostales [y aquí los carismáticos] muestran una gran preocupación por tener siempre algo nuevo en los cultos: nuevos milagros, nuevas ofertas, nuevas revelaciones, nuevos objetos, nuevos eventos, etc. Todo eso es el fondo lo mismo, pero presentado como nuevo. Con gran habilidad los pastores consiguen siempre anunciar algo nuevo. Los nuevos productos religiosos nunca permanecen por mucho tiempo. Luego de algunas semanas son reemplazados por nuevos productos, de tal manera que en el culto se tiene siempre algo nuevo... (p. 637). ${ }^{19}$

Precisamente, los carismáticos estarían haciendo lo mismo pero dentro de la Iglesia católica; trastornan la rutina del ritual para avivar la institución. ¿Esto traería consecuencias para la estabilidad de la misma? ¿Tal vez en el futuro este reavivamiento acompañado de sacerdotes con gran carisma los llevaría a entrar en conflicto con la institución?

3. El tercer momento, Lectura de la Biblia, o predicación de la palabra de Dios. Luego de leer el pasaje bíblico correspondiente al momento de la misa, el cura procede a dictar su sermón, que versa normalmente sobre el tema leído. En esta parte de la misa es donde el sacerdote despliega sus dotes histriónicos y de predicador. Su parecido con el pastor evangélico en este momento es evidente. El lenguaje es claro, contundente y cercano a la gente. Nada de complicados análisis teológicos del evangelio o aburridos comentarios sobre el pasaje bíblico. Como dicen los fieles, el padre carismático 
"habla claro", lo que significa que dice groserías, es ameno, cuenta chistes, se ríe de sus fieles, hace bromas a sus más cercanos, etc. En general son comunicadores excelentes. Su mensaje es claro y básico. No es extraño que en la actualidad algunos investigadores establezcan relaciones entre el discurso religioso cristiano contemporáneo con el de la publicidad; ${ }^{20}$ así el discurso de estos sacerdotes tendría el objeto de persuadir al receptor/adepto y modificar su actitud. Como los publicistas contemporáneos la Renovación Carismática Católica, al igual que los pentecostales, han tomado conciencia de la importancia de comunicar para mantener su auditorio:

...Se trata de dos discursos persuasivos cuya finalidad es la captación y fidelización del cliente o del feligrés, y para ello se valen de una serie de recursos comunes, aunque la oferta sea la misma - el paraíso- y al mismo tiempo no lo sea —aquí y allí—... (Rey, 2006: 93).

La comparación de los sacerdotes carismáticos y los pastores evangélicos con los animadores de televisión y su discurso con el de la publicidad no es gratuita. Los dos han invadido el espacio de las telecomunicaciones; publican revistas, utilizan la prensa, la radio y la televisión.

4. La comunión o Eucaristía. Momento tradicional y característicamente católico, pero acompañado de música rítmica y suave que es interrumpida por numerosos cantos, oraciones, testimonios y peticiones hechas por los feligreses. Al final de la Eucaristía se realiza lo que comúnmente se conoce como la "Sanación" y la "Liberación", aunque esto puede variar, pues, en algunas ocasiones se puede hacer durante la Eucaristía.

5. Usualmente, se deja para el final la "Sanación" y la "Liberación". Luego de la comunión el sacerdote conmina a los fieles a la curación. En esta fase del ritual se da la invocación del Espíritu Santo para las correspondientes curaciones; el sacerdote cumple aquí su importante función de propiciador para la "bajada del Espíritu Santo". Parece indudable que en la visión de los fieles el sacerdote es de suma importancia para ello. Aunque cada persona puede recibir los dones del Espíritu Santo, se acentúa las cualidades de curación y poder de algunos sacerdotes para expulsar los malos espíritus, sobre todo de los más carismáticos; así el padre invoca al Espíritu Santo mediante oraciones y cantos, para que se adueñe de él y le otorgue el don de sanar a los hombres. ${ }^{21}$ Durante este momento, algunos fieles son poseídos por el Espíritu Santo y se dan las respectivas curaciones. La "Sanación" y la "Liberación" constituyen el momento crucial de la misa y por el cual principalmente muchos de los fieles asisten; hay que recordar que el nombre de la misa es "de sanación". Habría que contrastar entre lo que realmente entienden los sacerdotes como "sanación" y lo que los adeptos entienden por tal; es posible que haya discrepancias. Por supuesto, es obvio que no se trata de una pura sanación "física", como lo veremos en algunos testimonios.

Los feligreses por orden del padre repiten las oraciones que este clama. Alzan sus brazos en dirección al cielo y en ocasiones elevan las palmas de sus manos hacia donde se encuentra el sacerdote. Cierran sus ojos como para lograr la mayor concentración posible, hasta que muchos consiguen el "éxtasis místico". El padre muchas veces manifiesta el don de lenguas y es acompañado por numerosas personas, mientras que otros feligreses lloran y acompañan la voz del padre con oraciones en español. Luego viene el don de sanación y liberación, el padre evoca distintas partes del cuerpo y va orando al Espíritu Santo para que aquellos que sufren algún tipo de enfermedad sean sanados; va mencionando el nombre de esas enfermedades sin señalar a la persona aludida, invocando al Espíritu Santo. A veces, el sacerdote dirá frases tales como: "a mi derecha hay una señora que tiene cáncer de pulmón, pero Dios en este momento la ha sanado"; del grupo de feligreses que indique algunos caerán desmayados al suelo. A pesar 
de que muchos se golpean muy fuerte, los creyentes aseguran que luego no experimentan dolor alguno en su cuerpo. Posteriormente el párroco y los demás feligreses que posean el don de sanación y liberación comenzarán a liberar espíritus; así, los poseídos quedarán libres de demonios, "zánganos"22 y de todos aquellos espíritus malignos que poseían. Esta es una de las etapas de la misa de sanación que más conmoción genera, puesto que el padre exige la expulsión de estos espíritus del mal, todos aquellos que se encuentren o se sientan poseídos caen al suelo en medio de espasmos, gritos y convulsiones. Finalmente, la gente se mantiene en oración durante los minutos posteriores de la sanación liberación. Hay quienes oran en lenguas - glosolalia-, "quienes lloran, quienes cantan y, aun, los hay quienes permanecen en el suelo inconcientes luego de ser sanados". Aquellos que son "tumbados" aseguran que es la fuerza del Espíritu Santo que se adentra en ellos y les vence todo tipo de resistencia. La gente cae al suelo sintiéndose bendecida por Dios, caer al suelo es visto por los carismáticos signo de la bondad del Señor, puesto que al desmayarse no están más que siendo tocados por la grandeza del Espíritu Santo. Las misas de sanación no otorgan curación tan solo a aquellos que padecen enfermedades físicas, las sanaciones cobran también la forma de liberaciones, en las que los demonios son expulsados de aquellos que han sido poseídos. Hay además quienes afirman haber sido sanados de un estilo de vida alejado de Dios, declaran que ha sido la presencia del Espíritu Santo que ha corregido sus vicios de drogas, alcoholismo, ocio o malas relaciones con sus familiares. Numerosos testimonios son ofrecidos a lo largo de la celebración eucarística, se hace referencia a sanaciones físicas donde la medicina occidental no logró su objetivo, como cáncer de próstata y de pulmón, asma y parálisis. Un ejemplo de estos testimonios:

Mi problema era el de una fuerte desviación en la columna, por eso no podía ni caminar y tenía que cargar permanentemente una faja. Después de asistir a las misas del Padre Carlos, Dios obró en mí a través del Espíritu Santo y su fuerza sanadora, yo quedé completamente sanada gracias a la gloria del Espíritu Santo, de Jesús y por la intervención del Padre... Ya más nunca he vuelto a usar la faja. (Daniela, 23 años).

\section{La difusión del culto}

Las redes de parentesco y de amistad parece que han sido fundamentales en la difusión de la Renovación Carismática, sin embargo no hay que olvidar que estas misas se han desarrollado bajo el cobijo de la Iglesia católica, que tiene una gran influencia y cobertura en toda Venezuela.

Muchos fieles aseguran que su primera asistencia a las misas de sanación fue incitada por algún pariente o una amistad cercana quien ya había asistido a este tipo de celebraciones. Estos nuevos asistentes a su vez invitaron a parientes y amigos, logrando mes tras mes un mayor número de concurrencia a las misas de sanación (Campos, 2006). En el caso de los pentecostales, la inserción en estos grupos evangélicos puede ocasionar conflictos con los parientes y amigos, ya sea porque son católicos o pertenezcan al culto de María Lionza; los pentecostales niegan toda posibilidad de comunicación con aquellos. Por su parte, los carismáticos condenan a los pentecostales y a los marialionceros, aunque algunos creyentes pueden exhibir una posición mucho más tolerante. Recordemos la capacidad de estos creyentes de transitar entre una a otra denominación, así como el diálogo, no sin conflicto, que ha existido entre el catolicismo y el culto a María Lionza (ver nota 9). Precisamente, la divulgación del mensaje carismático ha tenido gran éxito gracias a la difusión de testimonios que cuentan acerca de las milagrosas sanaciones o de la manifestación de algún don; numerosas personas afirman haber sido sanadas por el Espíritu Santo y otras aseguran haber sido bendecidas en una o varias ocasiones por los carismas o dones del Espíritu; la 
transmisión de estas vivencias genera curiosidad y/o esperanza y mueve a la población a asistir a estas misas.

Son muchos lo que acuden a las misas de sanación con la esperanza de ser sanados o de recibir algún carisma. El Espíritu Santo es la solución a sus problemas y necesidades, ya sean de salud, económicos, familiares, de desempleo, etcétera. Las peticiones que se hacen durante las misas de sanación son muy variadas e incluyen desde la sanación personal hasta la de algún pariente ausente en la misa. A través de las peticiones comprobamos que la razón fundamental por la cual los feligreses concurren es la de encontrar respuesta a los dilemas que le plantea la vida, las angustias que les acechan, y la solución a sus problemas cotidianos. Ejemplo de algunas de las peticiones de los creyentes:

...le suplico que oren por mi madrecita que está muy delicada de salud, los médicos no le consiguen ningún mal, se le han hecho muchos exámenes y no le sale nada pero igualito está muy enferma. Y lo que hace es quejarse, pasa día y noche sin dormir, puede Parar en loca y nos tiene locos a todo. Ella se llama María Teotiste Márquez Toro, ya no sabemos más qué hacer, porque ya no conseguimos nada que hacerle, la única solución que yo veo es llevarla para donde el padre... pero nunca lo consigo, y cuando es la misa de sanación no puedo hablar con él, le agradezco de todo corazón y que Dios los bendiga...

...pido oración para celebrar el Pentecostés en una misa de a labanza y sanación... para que haya una gran unción del Espíritu Santo y se derrame infinitamente los dones, frutos, carismas y virtudes del Espíritu Santo, orar mucho por el evangelizador padre... y por una petición especial de mi persona Adriana Ivette Dávila Zerpa, implorando protección y una gran necesidad en el nombre de Jesús lo imploro un buen clima para ese día...

Sin embargo, los adeptos también hablan de un recogimiento, de una nueva forma o estilo de vida que alcanzan, - parecido otra vez- - la nueva vida de la que hablan los pentecostales, conectados a un más allá, una vida unida a Cristo o a Dios, sin negar ni dejar a un lado la resolución de los problemas más rutinarios y más cotidianos, ligados al cuerpo.

\section{¿Herederos del misticismo cristiano o misticismo light?}

El cuerpo ha sido siempre el lugar de lo social: control, modelo, representación e imaginario del grupo; por lo tanto, lugar de lo religioso, de la visión de lo natural y condensación de lo cultural. Es el espacio de los deseos, de las frustraciones y de los conflictos sociales. ${ }^{23}$ Como dice Baudrillard (1992), para la medicina el cuerpo de referencia ideal es el "cadáver", para la modernidad el "robot", para la sociedad posmoderna contemporánea sería el "maniquí", y para la religión el "animal", cuerpo natural; "instintos y apetitos de la carne" que hay que dominar (p. 133).

El cuerpo para la religión sería el lugar del control o del abandono, de la moderación o del desenfreno, del cuidado o de la dejadez; son polos de significado donde el cuerpo sirve de metáfora de las relaciones sociales y donde también esas relaciones se concentran y se viven. En la historia del cristianismo esos dos polos han pendulado, erigiéndose como modelo para toda la sociedad o, a veces, funcionando de manera paralela, haciendo del cuerpo el lugar de todos los deseos o el de todas las frustraciones. En este sentido, en el cristianismo hay una tradición muy fuerte donde el cuerpo es la fuente y el lugar de lo sagrado; no obstante, se intenta renunciar a él, se le martiriza, se le señala como lugar del mal, sobre todo en un tiempo- el cuerpo femenino. Siendo el receptor de los sentidos, es también el lugar donde se recibe a Dios, donde se le percibe y se palpa, es el instrumento con el que se le adora, lugar de regocijo, de culpa y objeto de castigo. No siempre ha sido así. Curiosamente, estas búsquedas en el cristianismo han funcionado o 
han provocado una supuesta renovación en distintas épocas que, finalmente, terminan por calmarse, por institucionalizarse. Por ejemplo, el monacato pone fin a la ascesis exagerada de los primeros anacoretas de la antigüedad; San Francisco y su forma de piedad son "reconocidos" y controlados con la creación de una congregación. También, en América colonial, en México y en Perú, algunos místicos arrebatados dejaron huellas de esa búsqueda extática, no siempre bien soportada aunque tolerada, en muchos casos incluso protegida. Algunos de esos "héroes" místicos fueron propuestos como modelos de santos. Como señala Vallverdú (2001):

...la reivindicación del cuerpo adoptaría múltiples formas, a veces las que remarcan elementos de intensidad, expresión y emoción religiosa ausentes o debilitados en las religiones tradicionales o Iglesias establecidas. Con este espíritu emocional destacan los movimientos religiosos carismáticos, católicos (como la Renovación Carismática) o protestantes (el pentecostalismo, especialmente), que en las últimas décadas han experimentado un considerable éxito y crecimiento en diferentes contextos, especialmente en Latinoamérica (Vallverdú, 2001).

La renovación católica carismática, de alguna manera, proviene de esta tradición — quellamaremos mística ${ }^{24}$ tanto en la línea pentecostal como carismática católica. Refuerza algunas de las ideas centrales del cristianismo: la renuncia al "mundo" y la acentuación de que la vida es solo un tránsito. Sin embargo, las formas carismáticas y pentecostales actuales no llegan a convertirse en una verdadera renuncia al mundo o en un ascetismo radical. De esta manera, algunos autores consideran que el pentecostalismo más que un movimiento es una "actitud o una mentalidad", podríamos decir una corriente del cristianismo:

...Es lo que Roger Bastide ha denominado lo "sagrado salvaje", la comunicación con la divinidad a través de la experiencia sensual, afectiva, no racional ni sistematizada, sin intermediarios, sin institucionalización que surge en contraposición con lo "sagrado domesticado", la comunicación con la divinidad a través de la razón y el intelecto, de la Palabra de Dios o la oración, y no de Dios mismo. En este sentido, el pentecostalismo [así como la renovación carismática] no sería más que la última manifestación de una corriente antiintelectualista que caracteriza fuertemente a todos los movimientos religiosos populares... (Ullán de la Rosa, 2003).

Sería entonces una especie de misticismo light, un misticismo para las masas que compite con lo New Age (ver nota ll), con los libros de autoayuda y las religiones orientales, tal como se han "adaptado" en Occidente.

En el discurso carismático se propone una huída radicaldel mundo, tal comoloplantean los pentecostales, sin embargo pareciera más una insistencia de los sacerdotes líderes; por ejemplo, en sus discursos reiteran a su feligresía la poca importancia que los católicos deben dar a los muertos. En contra de la tradición por lo menos en Venezuela - afirman algunos de estos sacerdotes que la misa debe ser consagrada a los vivos y no a los muertos, tanto que en ocasiones han sido increpados por los feligreses al negarse a oficiar misas durante los domingos para sus familiares difuntos, tal como es la costumbre, alegando que la misa es exclusivamente para adorar a Dios. Además la muerte, dicen, "no debe enfrentarse con miedo sino con alegría", correspondiendo con la tradicional preocupación cristiana por la segunda venida de Cristo.

Los pentecostales contemporáneos, incluyendo a los carismáticos, parecen ser los herederos del misticismo cristiano. En sus testimonios hablan de "separarse del mundo"; se consideran más puros que los demás cristianos, asumen el ritual “en serio”, como dicen algunos de ellos, y los líderes carismáticos tienen la convicción de su papel renovador del culto católico. El acercamiento a Dios a través de la posesión del 
Espíritu Santo es un rasgo eminentemente místico, la búsqueda de adorar a Dios con todo el cuerpo ya no a través de grandes pruebas físicas - aunque las misas de sanación sean verdaderos maratones- que, indudablemente, al igual que los famosos anacoretas del pasado, estimulan al cuerpo para el trance, alterar la conciencia y así recibir el Espíritu Santo. ¿La inconciencia en la posesión del Espíritu Santo acaso no alude a esa búsqueda de los místicos de abandonarse a Dios? Pero ese abandono no es solitario, debe ser en colectividad, apretujados, cantando, exhaustos, aplaudiendo: una manera muy física, corporal y colectiva de enfrentar la divinidad.

Los místicos medievales contaban con la virtud de la palabra escrita para dar testimonio de esa entrega y esa relación con la divinidad. En este culto, el testimonio es a viva voz el relato de cada uno de los fieles, y el del sacerdote, el profeta-pastor que ordena y enfoca el poder del Espíritu Santo para curar, para en el arrobo de la posesión mostrar la eficiencia, la utilidad del Espíritu Santo: el poder de curar los males espirituales y físicos que siempre se marcan en el cuerpo, a la vista de todos, como también debe ser la curación. Curiosamente, a diferencia del místico medieval o del asceta de la antigüedad, en el fiel carismático las pretensiones ascéticas se resumen en ordenar moral y cotidianamente su vida:

Yo era una persona que estaba sumergida en los vicios y especialmente en el desorden sexual y de la vida... yo sentí como Cristo me rescató, como restauró mi vida y como me ha presentado todo lo nuevo y lo bueno que se puede vivir... Aproximadamente desde hace ya seis años se están celebrando estas asambleas [misas de sanación]... usted podría preguntarle a cualquier[a]... y verá que ha disminuido notablemente el número de alcohólicos en la zona (Henry Escalona).

En algunas personas entrevistadas parece que la conversión es tomada como un evento significativo, en otros parece estar presente más la "alegría” o los cambios de tipo económico; dicho de otra manera, el "orden" alcanzado en su vida.

La ritualidad carismática parece evidenciar una suerte de paradoja con respecto al cuerpo. El sacerdote, al igual que los pentecostales, afirma en sus sermones la lucha contra "el mundo", ese mundo lleno de pecados donde el cuerpo manda en sus incontables y execrables apetitos. Se insiste contra la bebida, contra la lujuria sexual, contra las drogas que destruyen la juventud y descohesionan a la familia. En otras palabras, apuestan por un ascetismo en la vida cotidiana que parecía alejado de los sermones de los sacerdotes católicos tradicionales, que aparecía matizado en sus documentos oficiales.

El cuerpo, pues, es tanto lugar de contacto como de separación con la comunidad carismática: de contacto con los demás en los eventos extáticos de la misa; alegría, cantos, abrazos, el hablar en lenguas, marcan la cercanía del Espíritu Santo, pero sobre todo la inmersión en un colectivo, lo religioso en el sentido clásico que decía Durkheim — religare - la unión con el grupo, el equivalente de Dios. A la vez el cuerpo es lugar de separación, de distanciamiento de los demás, ocurre cuando el cuerpo es tomado por el demonio, por los espíritus diabólicos —en su mayoría provenientes del culto a María Lionza o de las "sectas" pentecostalesLa impureza, la contaminación del mundo, del pecado y de la maldad externa se hace carne y se encarna en la enfermedad, que nunca es puramente física sino espiritual. Así cuenta un fiel acerca de una experiencia de posesión diabólica:

Estuve siete años bajo la posesión de Satanás, hicieron conmigo un pacto en la montaña de Sorte donde fui consagrado a él... mi vida era un desastre total, estuve a punto de suicidarme, los demonios me acompañaban siempre, veía cosas... busqué ayuda psicológica y no obtuve ningún resultado satisfactorio, cuando creí que estaba perdido escuché 
hablar de una misa de sanación en Mucuchíes. Esta noticia fue mi última esperanza... Al venir a este lugar [donde se realiza la misa de sanación] por medio del Padre Carlos, Dios me liberó y lo que no pudo hacer nadie por mí en siete años, él lo hizo en tres horas. Hoy con propiedad puedo decir que Cristo vive (José Márquez).

La mención del demonio o el diablo es una constante. A él se le atribuyen todos los "males" que pueden "curarse", casi exclusivamente con las misas de sanación..$^{25}$

El cuerpo es marcado, en él se juega y evidencia la "verdad" y la eficiencia de la ritualidad carismática: la unión con el Espíritu Santo que es unión con la comunidad, con el líder carismático y con el éxito en la vida cotidiana.

Para la sensibilidad religiosa contemporánea la renovación carismática parece, más bien, ser una concreción cotidiana de la utopía cristiana. El gozo, la alegría en el cuerpo, la adoración a Dios a través del Espíritu Santo, de eso hablan los carismáticos. Es tal vez una salida que han conseguido, haciendo popular la respuesta contra "esa intensa sensación de exilio" de la que hablaban los místicos cristianos; esa extranjería en el mundo en general y en el cuerpo mismo como parte del mundo, que parecen haber siempre sufrido y hablado los cristianos. Si bien el cuerpo es una prisión para el cristiano, que lo obliga a estar en el mundo, una tumba de la que hay que liberarse, así como de los sentidos; las misas de sanación, la ritualidad carismática, vence estas limitaciones y las utiliza para estar en el mundo y a la vez para liberarse, sintiendo a Dios, llegando a estar, aunque brevemente, en el tiempo del ritual, en comunión.

El catolicismo, así, parece convertirse en una suerte de utopía cercana y cotidiana, una catarsis que ayuda a acomodarse en el mundo, el cual no se quiere abandonar pero se pretende obviar, tal como se hace con el cuerpo.

\section{Notas}

${ }^{1}$ Este artículo fue presentado en forma preliminar en la VII Reunião de Antropologia do MERCOSUL (RAM) realizada en Porto Alegre (Brasil), Universidad Federal do Rio Grande do Sul, en junio de 2007. Dentro del Grupo de Trabajo (GT 32) "Experiências religiosas na Contemporaneidade: categorías, práticas, instituções e movimientos socias", gracias al financiamiento del Consejo de Desarrollo Científico y Humanístico (CDCHT) de la Universidad de Los Andes, MéridaVenezuela.

2 Desde la oficialidad de la Iglesia católica algunos eclesiásticos de alto rango se oponen a calificar de "movimiento" a la Renovación Carismática, señalan que es una "corriente", tal vez para reafirmar la unidad de la institución y diferenciarse del "pentecostalismo protestante" (Jiménez, 1990: 30). Algunos sacerdotes carismáticos entrevistados incluso se niegan a identificarse como carismáticos sino como católicos "a secas".

3 El desprecio hacia la piedad extática ha sido una constante en el cristianismo. Como afirma Lindholm: “...Mientras que la participación en rituales extáticos en culturas tradicionales o 'primitivas' es considerada como algo 'normal' y funcional, la pervivencia de prácticas carismáticas en sociedades occidentales es fuertemente estigmatizada, 'las pruebas aportadas por sociedades menos complejas sugieren que una visión positiva de la participación carismática es la regla y no la excepción en las comunidades humanas, y que dicha participación sólo adquiere un valor negativo cuando la sociedad se vuelve muy centralizada, impersonal y racionalizada' " (citado por Mena Cabezas, 2003).

${ }^{4}$ Esto depende de la feligresía del sacerdote. En algunos casos la cantidad de fieles es tan numerosa que los templos no son suficientes para albergar tanta persona. Se recurre entonces a espacios utilizados normalmente para grandes concentraciones públicas, como plazas de toros, antiguos teatros o cines, estadios deportivos, 
etc.; tal como lo vienen haciendo los grandes pastores evangélicos norteamericanos.

${ }^{5}$ El documento dice en su introducción que este fue un importante producto de un Encuentro Episcopal Latinoamericano “...para estudiar en un clima de oración y reflexión, los fundamentos teológicos, los frutos y posibles problemas de la Renovación Carismática Católica, y dar orientaciones pastorales que ayuden a su crecimiento y madurez. Uno de los resultados de este Encuentro es el Documento doctrinaly pastoral que presentamos... con la esperanza de que sea de mucha utilidad para quienes lo estudien cuidadosamente. Advertimos que no se trata de un Documento oficial y que ha sido firmado a título personal por la mayoría de los participantes, y es enviado por cada obispo a su respectiva diócesis para fijar los criterios que pueden animar y orientar la Renovación allí" [énfasis nuestro] (Encuentro Episcopal Latinoamericano, 1987: 1).

${ }^{6}$ Por Venezuela participaron: Mons. Pío Bello Ricardo (obispo de Los Teques), Mons. Francisco de Guruceaga (obispo de La Guaira), Mons. Rafael Ángel González (obispo de Barinas), Mons. Antonio Arellano D. (obispo de San Carlos), Mons. Roberto Luckert León (obispo de Cabimas), Mons. Constantino Marady D. (obispo de Barcelona), Mons. Tulio M. Chirivella V. (arzobispo de Barquisimeto). Colombia, por ser la sede del evento, fue la que contribuyó con un mayor número de participantes, de distinta jerarquía. También asistieron arzobispos, obispos y prelados de Ecuador, México, Curazao, Uruguay, Paraguay, Perú, Panamá, Nicaragua, Honduras, Argentina, Bolivia, República Dominicana, EE.UU., Brasil y Guatemala (Encuentro Episcopal Latinoamericano, 1987: 17-19).

${ }^{7}$ En los apartados № 9 y 10 del Documento del Encuentro Episcopal Latinoamericano (1987) se muestra una preocupación por limitar y dirigir el movimiento de renovación. El apartado № 6 dice: “...Pablo VI ha expresado su complacencia por la Renovación espiritual que aparece en los lugares y medios más diversos y que conduce a la oración gozosa, a la íntima unión con Dios, a la fidelidad al Señor y a una profunda comunión de las almas. Así lo han hecho también varias Conferencias Episcopales. Pero esta Renovación exige buen sentido, orientación y discernimiento por parte de los Pastores, a fin de evitar exageraciones peligrosas" (p. 2).

8 Para el 2000, Angelina Pollak-eltz señalaba que en Venezuela no existía una cooperación “...entre carismáticos y las denominaciones pentecostales evangélicas, por lo menos no al nivel oficial. Sin embargo, es cierto que en este país las campañas de reavivamiento organizadas por los carismáticos católicos atraen algunos evangélicos, y que un buen número de los participantes en campañas pentecostales son católicos. La actuación, el comportamiento y la manera de predicar, de los sacerdotes carismáticos se asemeja al comportamiento de pastores pentecostales, además la terminología usada por ambos grupos es similar" (Pollak-eltz 2000: 140). En la actualidad esto es todavía más cierto.

${ }^{9}$ Curiosamente parece ser un miembro del Opus Dei.

10 El culto a María Lionza, parecido a la Umbanda brasileña, es una religión que se desarrolló en Venezuela a partir de los años cincuenta en el proceso de migración del campo a la ciudad. Tiene como mito central la figura de una deidad de origen indígena. Ha incorporado elementos católicos, indígenas y de origen africano, así como del espiritismo kardeciano, rasgos del curanderismo tradicional e incluso de la medicina occidental moderna. Es un culto de posesión y llamado entre sus adeptos "espiritismo". La "materia" - o médium - es la persona que en el culto "recibe" en su cuerpo a los distintos espíritus que son invocados en los rituales, cuando uno de estos "baja" — como dicen los adeptos - toma posesión de la "materia". Estos espíritus son agrupados en Cortes, noción que sirve para distinguir los distintos grupos de espíritus que existen en el culto (Corte Vikinga, Corte Africana, Corte India, Corte Médica, Corte Malandra, Corte de los Juanes, Corte Libertadora, etcétera). Hay una cantidad 
considerable de "Cortes" que varían, desaparecen o aparecen de acuerdo con la formación, instrucción y personalidad de los oficiantes y creyentes. Los médiums a través de los espíritus ayudan a los creyentes a curarse física y "espiritualmente", luchan contra enfermedades y los daños mágicos que personas infligen a otras (Clarac, 1992; García Gavidia, 1987, 1996; Flores Díaz, 1990, 1996; Pollak-eltz, 1982).

${ }^{11}$ Dice el Documento Episcopal Latinoamericano, de CejaColombia, de 1987: "Somos conscientes de la hora difícil que viven nuestras diócesis a causa principalmente del secularismo y del materialismo que destruyen los valores cristianos y convierten al hombre en esclavo de ídolos como el dinero, el sexo y el poder; lo mismo que del avance constante de las sectas cuyo número de adeptos crece en todos nuestros países, constituye un reto muy serio a nuestra labor pastoral, especialmente en el campo de la evangelización, y destruye la comunión y unidad del Cuerpo Místico de Cristo. Como también de las tensiones y dificultades interiores que vemos en la Iglesia y que impiden su unidad" (p. 2).

${ }^{12}$ En la Nueva Era “...la noción fundamental es la de circular por distintos talleres, workshops, probar distintas filosofías y prácticas religiosas, pero sin necesariamente adherirse incondicionalmente a una de ellas" (Míguez, 2000: 66). Ver además a Mircea Eliade (1997), quien afirma acerca del interés y la moda del ocultismo y el esoterismo contemporáneos: "Estamos... en presencia de situación bastante paradójica: por un lado, una explosión ocultista, una suerte de religión 'pop', característica especialmente de la cultura juvenil norteamericana, que proclama la gran renovación de la edad postacuario; y por otro, un descubrimiento y una aceptación más modestos pero en crecimiento progresivo del esoterismo tradicional, tal como lo ha reformulado, por ejemplo, Guénon, que rechaza la esperanza optimista de una renovación histórica y cósmica sin una preliminar disolución catastrófica del mundo moderno..." (pp. 95-96).
${ }^{13}$ No son las únicas ofertas religiosas en Venezuela pero son las que nos interesan para este artículo, a excepción del llamado New Age o Nueva Era que solo lo mencionamos pero no desarrollamos cuál sería su interrelación con el movimiento carismático.

${ }^{14}$ Se llama Carlos Zambrano, de la parroquia de Mucuchíes. Es nativo de Mesa Bolívar (Estado Mérida), cuenta con un gran apoyo, respeto y admiración en el pueblo de Mucuchíes, donde actualmente es párroco. A la edad de quince años al padre Carlos, por primera vez, se le reveló el don de sanación y el don de lenguas - glosolalia-, durante un retiro que hizo con un grupo de jóvenes carismáticos. Tenía a su hermana mayor, Olga, gravemente enferma, hizo la promesa de que si ella era curada él se consagraría a Dios. Tal fue su sorpresa al ver que de regreso a su casa con sólo tocar a su hermana ésta era sanada. En adelante - cuentan sus adeptos - la vida del padre se transformó, hasta llegar a ser el gran líder carismático que hoy en día es.

${ }^{15}$ Aunque este sacerdote es el párroco de un pueblo agrícola, Mucuchíes, su comunidad desborda los límites del campo y de este pueblo. Con este ha establecido una relación particular, que ha servido como centro de su feligresía y de su poder como líder carismático, así como lugar de proyección de sus misas de sanación. Habría que estudiar de manera particular esta relación. Por otra parte, hay que resaltar que todos los años en noviembre realiza en la plaza de toros de Mérida una misa a la que asisten un número enorme de adeptos de la ciudad y de otras partes de Venezuela.

${ }^{16}$ Algo que tentadoramente nos lleva a relacionarlo con los sucesos políticos de los últimos años en Venezuela; la emergencia de un líder "carismático" nacional: el presidente Chávez, quien ha coqueteado abiertamente con el discurso, la gestualidad y el lenguaje de los pastores evangélicos, hasta el punto de que es copiado por pastores evangélicos y sacerdotes carismáticos. Una veta de investigación más que habría que estudiar. 
${ }^{17}$ Hay que reconocer que algunos de estos sacerdotes asoman una tendencia - aunque débil- a cierto ecumenismo cristiano.

${ }^{18}$ A las misas de sanación de Mucuchíes les antecede una vigilia. Los distintos fieles van arribando al pueblo la noche anterior. Se congregan en la cancha del colegio que les sirve de templo, allí se disponen a pasar la noche en medio de cantos y oraciones, son muchos los que permanecen despiertos hasta el amanecer, otros duermen sobre el suelo del templo. Las vigilias son una preparación para la misa de sanación. A los asistentes se les enseña la letra de las canciones que al siguiente día entonarán, se ora con ellos y se hacen juegos. También es frecuente que durante estas vigilias del Espíritu Santo se manifieste el don de lenguas, el de sanación y/o el de profecía.

19 Ver video en http://www.youtube.com/ watch?v=ehAQQ8mDxmQ. También ver páginas web de noticias y videos sobre el Movimiento de Renovación Carismática Católica de Venezuela: - BEJARANO DELGADO, Elkis (15/07/2008). “Caraqueños mantienen viva su fe con ceremonias carismáticas”. EL UNIVERSAL. Caracas. En http://www.eluniversal.com/2008/06/15/ ccs_art_feligresia-catolica_900421.shtml.

- Danzas Andinas en Misa de Sanación. En http://www. youtube.com/watch?v=t8CJYnIu6Rs\&feature=related.

"Trujillanos renuevan consagración al Santísimo Sacramento del altar". 17/01/2009. En Diario Los Andes. Valera-Venezuela. En http://diariodelosandes.com/ content/view/66115/105696.

Mucuchíes, Tierra de Gracia. Misa de Sanación. En http://www.youtube.com/watch?v=ehAQQ8mDxmQ.

- No 39. Misa de Sanación en San Fernando de Apure. 12 abril 2008 \#1 de 2. En http://www.youtube.com/ watch?v=amBsZDr9K3k.

- No 40. Misa de Sanación en San Fernando de Apure. 12 abril 2008 \$2 de 2. En http://www.youtube.com/watch ? $\mathrm{v}=\mathrm{T} x 5$ aIIIDsm8\& 8 feature=related.

- $N^{\circ}$ 45- Testimonios de Sanación. 30 mayo 2008. En http:/www.youtube.com/watch?v=X0vj2sGtrrU\&ffeat ure=related.
PÉREZ, Ramón Antonio (24/06-2007). "Renovación Carismática Católica de Venezuela celebró cuarenta aniversario". En El Católico Guardián. En http:// elguardiancatolico.blogspot.com/2007/06/larenovacin-carismtica-de-venezuela.html. Renovación Carismática Católica de Venezuela. BarquisimetoVenezuela. En http://www.rccvenezuela.com.

Renovación Católica Carismática. Caracas. En http:// rcc-caracas.org/9922.html.

${ }^{20}$ Barrera Rivera (2002) agrega que el contraste entre el protestantismo tradicional y el pentecostalismo renovado es enorme, ya que los cultos del primero “...trabajaban siempre en favor de la repetición, de la recuperación o rememoración de la tradición...", mientras "...el pentecostalismo trabaja lo contrario; es decir, la búsqueda de lo nuevo. La novedad en el centro del culto genera inevitablemente inestabilidad, y no solo de las personas más también de la propia institución" (p. 637). Afirmación que vale aún más para los carismáticos.

${ }^{21}$ Aunque “...la Iglesia católica, en particular, y el cristianismo, en general, rechazaron en los primeros siglos los procedimientos retóricos porque entendían que el suyo era un mensaje revelado que se refiere a la Verdad y que por tanto no requería de los afeites retóricos que consideraban no sólo innecesarios, sino además, perjudiciales para un mensaje verdadero..." (Rey 2006: 86), se dieron cuenta de la importancia de la "propaganda", de propagar la buena nueva (el Evangelio) y acompañar la imposición con la persuasión.

${ }^{22}$ El carisma “...constituye una estructura estructurante de la comunidad. Todos pueden tener acceso a los carismas, lo cual permite profundizar en la fraternidad y el servicio mutuo. Los carismas no excluyen las instituciones o las jerarquías posibles en las iglesias pentecostales sino que las incluyen. El carisma es la fuerza pneumática que instaura instituciones y las conserva vivas. Por eso el principio de estructuración de los cultos no lo constituyen las jerarquías sino los carismas. No hay iglesia sin carismas. Si se pierden 
algunos la comunidad no sólo padece un perjuicio moral, espiritual y grupal, sino que es atacada en su misma esencia, de ahí que sea vivido como una perversión" (Mena Cabezas, 2007).

${ }^{23}$ Figura mítica de los Andes venezolanos. Representa a una especie de "brujo" que tiene poderes mágicos, posee un libro mágico, normalmente identificado con personas solitarias, ermitaños, homosexuales o aislados de sus comunidades. Posee la capacidad de convertirse en algunas clases de animales y el poder la ubicuidad. En ocasiones, ataca a mujeres para tener relaciones sexuales con ellas, dejándoles moretones por todo el cuerpo. Muchas de estas mujeres parecen sufrir de cierto histerismo y pueden ser tratadas por los oficiantes del culto a María Lionza, por sacerdotes católicos, por los pastores pentecostales y por psiquiatras (ver Clarac, 2004).

${ }^{24}$ En relación con la investigación sobre el cuerpo, Bryan Turner (1994) nos dice: “...la antropología, más que la sociología, desarrolló una teoría del cuerpo (o al menos, bastante interés en la investigación del cuerpo), ya que en las sociedades premodernas el cuerpo es una superficie importante en la que las marcas de condición social, posición familiar, afiliación tribal, edad, sexo y condición religiosa pueden exponerse fácil y públicamente. Mientras que la exhibición corporal es el casoclaroenlas sociedadesmodernas (vestido, posturas, maquillaje), crucial para mostrar bienestar y estilo de vida, en las sociedades premodernas el cuerpo era un objetivo más importante y ubicuo para el simbolismo público, a menudo por medio de la decoración o tatuaje..." (p. 15). Por su parte, acerca del cuerpo como experiencia individual y social, nos dice Salinas (1994): "Existen dos realidades fundamental y básicas que caracterizan cualquier experiencia individual de la vida social, una es simbólica -el lenguaje-, la otra física -el cuerpo-. Estas dos realidades están presentes en todas las situaciones, y actúan como necesarias referencias físicas y simbólicas para que el individuo participe de los procesos de objetivación y socialización de la cultura referencial en la que se encuentra inscrito. Estas realidades interactúan permanentemente como medios de percepción y expresión individual de la cultura referencial, hallándose sujetas a significados cambiantes y variables. Ambas son manifestaciones de los proceso de reflexión del sujeto colectivo e individual" (p. 85).

${ }^{25}$ Según una de las acepciones del DRAE: “....comunicación inmediata y directa entre el hombre y la divinidad, en la visión intuitiva o en el éxtasis".

${ }^{26}$ Acerca de lo que temen los gitanos españoles convertidos al pentecostalismo: "Rebeldía, locura, enfermedades, condena a las impurezas, las cadenas de las drogas, el alcohol, las cartas, los gritos, la idolatría, la violencia autodestructora, el desaliño, los insultos y maldiciones, la ira y la venganza, etc., se acumulan en el imaginario del mal y en el que la denominación gitana coincide con conversos de todo el mundo. Si examinamos todos estos rasgos vemos que son indicadores de categorías de exterioridad, alienación y negación, un arsenal simbólico propio de lo impuro y contaminado... Una exterioridad ajena al control y dominio de la propia vida y, al mismo tiempo, respecto al orden de la comunidad de creyentes. Excluidos de las obligaciones que la vida de los conversos exige, las manifestaciones de los posesos subrayan su separación y desorden, su lateralidad respecto al espacio grupal. Pero esta perfecta exterioridad, esta independencia, lejos de constituir expresión de libertad, se describe como síntoma de servidumbre y cautiverio: el hombre queda reducido al dominio del diablo" (Mena Cabezas, 2003).

\section{Bibliografía}

Ayerra, P. J. (1980), Los protestantes en Venezuela, Caracas: Tripoide.

Barrera Rivera, Paulo (2002), "Hibridación y aflojamiento de fronteras entre evangélicos latinoamericanos", en Boletín Antropológico, año 20, núm. 55. Mayo-Agosto, Mérida: Universidad de Los Andes, pp. 629-648, 
Baudrillard, Jean (1992) El intercambio simbólico y la muerte, Caracas: Monte Ávila Editores (segunda edición).

Brumana, Fernando Giobellina (1986), "El cuerpo sagrado acerca de los análisis de fenómenos de posesión religiosa”, en REIS, núm. 34, abril-junio, Madrid: Universidad Complutense.

Campos, Bernardo (2006), "Pentecostalismo y sociedad. El estudio del movimiento pentecostal en los últimos 30 años. Estado de la cuestión", en Haríresís. Boletín de la hemeroteca de www.nuevos-movimientos-religiosos.com, núm. 13, abril 2006.

Castillo, Ramón (1992), "Elementos para la historia del pentecostalismo en Venezuela”, en Álvarez, C. (edit.). Pentecostalismo y Liberación, San José: Editorial Dei.

Certeau, Michel de (1993), La fábula mística. Siglos XVIXVII, México: Universidad Iberoamericana.

Clarac De Briceño, Jacqueline (2004) "Salud mental y globalización, necesidad de una nueva etnopsiquiatría”, en Boletín Antropológico, Mérida: Universidad de Los Andes. Año 22, núm. 61, Mayo-Agosto, pp. 159-185.

Clarac De Briceño (1992), La enfermedad como lenguaje en Venezuela, Mérida: Consejo de Publicaciones, Universidad de Los Andes.

Encuentro Episcopal Latinoamericano (1987), "La Renovación Espiritual Católica Carismática”, Documento del Encuentro Episcopal Latinoamericano, La Ceja-Colombia: en http://www.rccperu.org/pdf/ documentoLaCeja.pdfEliade, Mircea (1997), Ocultismo, brujería y modas culturales, Barcelona: Paidós Orientalia.

Flores, Dilia (1990), "Hablas sagradas", en Primer Seminario Nacional sobre Religióny Etnomedicina. Memorias, Maracaibo: Facultad Experimental de Ciencias. La Universidad del Zulia, pp. 93-99.

Flores, Dilia (1996), La adivinación por el tabaco en el culto a María Lionza, Maracaibo: Vicerrectorado Académico, La Universidad del Zulia.

Ganuza, J. M. (1978), La Renovación Católica Carismática, Caracas: Universidad Católica Andrés Bello.

García Gavidia, Nelly (1987), Posesión y ambivalencia en el culto a María Lionza. Notas para una tipología de los cultos de posesión existentes en la América del Sur, Maracaibo: Universidad del Zulia, Facultad Experimental de Ciencias.

García Gavidia, Nelly (1996), El arte de curar en el culto a María Lionza, Maracaibo: Vicerrectorado Académico, La Universidad del Zulia.

García Selgas, Fernando J. (1994), "El 'cuerpo' como base del sentido de la acción”, en REIS, núm. 68, octubrediciembre, Madrid: Universidad Complutense.

Garma Navarro, Carlos (2000), "La socialización del don de lenguas y la sanación en el pentecostalismo mexicano", en Alteridades, núm. 10, pp. 85-92.

Geertz, Clifford (1989), La interpretación de las culturas, Barcelona: Gedisa editorial.

Jiménez, Gonzalo (1990), "La Renovación Carismática. Hall de la Iglesia", en Exceso, Caracas: Editorial Exceso, núm.19, Julio, pp. 29-32.

Larios Robles, Vanessa, "La carne de Cristo. Sobre el papel del cuerpo en el cristianismo", en A Parte Rei. Revista de filosofía, en http://serbal.pntic.mec.es/-cmunozll/ index.html

Macia, N. (1997), Crónicas del Evangelio en Venezuela, Maracay.

Mercado, Rubén (2006), La iglesia pentecostal en Mérida: siglo XX (Una aproximación a la historia del protestantismo en Venezuela), Memoria de Grado, Mimeografiada, Mérida: Escuela de Historia, Universidad de Los Andes.

Miguez, Daniel (2000), "Modernidad, postmodernidad y la transformación de la religiosidad de los sectores medios y bajos en América Latina”, en Revista de Ciencias Sociales, Iquique-Chile: Universidad Arturo Prat, Núm. 010, pp. 56-68. en http://redalyc.uaemex. $\mathrm{mx} / \mathrm{redalyc} / \mathrm{pdf} / 708 / 70801004 . \mathrm{pdf}$

Mena Cabezas, Ignacio R. (2003), "Sobre dones carismáticos. Una aproximación a la glosolalia y la liberación de espíritus en los cultos pentecostales gitanos", en Gazeta de Antropología, núm. 19, GranadaEspaña: Universidad de Granada, en: http://www. ugr.es/-pwlac 
Mena Cabezas, Ignacio R. (2007), "La fe en el cuerpo: La construcción bicorporal en el pentecostalismo gitano", en Revista de Antropología Experimental, JaénEspaña: Universidad de Jaén.

Mendoza Zuany, Rosa Guadalupe (2002), "Pentecostalismo popular en Akil, Yucatán", en RMC, núm. 14, pp. 105-144.

Pollak-Eltz, Angelina (1982), Medicina popular en Venezuela, Colección Monografía y Ensayos, № 86, Caracas: Biblioteca de la Academia Nacional de la Historia.

Pollak-Eltz, Angelina (2000), Estudio antropológico del Pentecostalismo en Venezuela, Caracas: Universidad Santa Rosa de Lima.

Prieto P., Williams (1990), "Un examen teológico del pentecostalismo en el protestantismo y en el Catolicismo", en Primer Seminario Nacional sobre Religión y Etnomedicina. Memorias, Maracaibo: Facultad Experimental de Ciencias/La Universidad del Zulia, pp. 69-75.

Rey, Juan, (2006), "Publicidad y religión. Semejanzas y diferencias entre el discurso publicitario y el discurso católico", en Trípodos, núm. 18, Barcelona, pp. 65-94.

Rivas Sarache, María Teresa (1991), El protestantismo en Venezuela: posición de la iglesia católica merideña frente a su inserciónen Mérida, Memoria de Grado. Mimeografiada, Mérida: Escuela de Historia, Universidad de Los Andes.

Salinas, Lola (1994), "La construcción social del cuerpo", en REIS, núm. 68, octubre-diciembre, Madrid: Universidad Complutense.
Segura Carmona, Harold (2007), "El Movimiento Pentecostal-Carismático: Evaluación Desde Una Perspectiva Pastoral", en http://www. pentecostalidad.com. Recuperado el 16/04/2007.

Sutton, Alicia Hamui (2005), "Respuestas religiosas latinoamericanas a los ajustes socio-culturales de la globalización", en Confines de Relaciones Internacionales y Ciencia Política, agosto-diciembre 2005, Monterrey, México: Tecnológico de Monterrey.

Turner, Bryan (1994), "Los avances recientes en la teoría del cuerpo", en REIS, núm. 68, octubre-diciembre, Madrid: Universidad Complutense.

Ullán De La Rosa, y Francisco Javier (2003), "Análisis del crecimiento pentecostal entre las clases populares e indígenas de Latinoamérica: Aplicación del modelo a una comunidad Ticuna de la Alta Amazonia", en Relaciones, Núm. 96, Vol. XXIV, Michoacán, México: El Colegio de Michoacán, pp. 227-265, en http://www.colmich. edu.mx/relaciones

Vallverdú, Jaume (2001), "Mercado religioso y movimientos carismáticos en la modernidad", en Gazeta de Antropología, № 17, Granada-España: Universidad de Granada, en: http://www.ugr. es/-pwlac, recuperado el 16/04/2005.

Weber, Max (1969), Economía y Sociedad, Tom. I, México: Fondo de Cultura Económica.

1979. Laética protestante y el espíritu del capitalismo, Barcelona: Ediciones Península, quinta edición.

Wilson, Bryan (1969), La religión en la sociedad, Barcelona: Editorial Labor. 